\title{
Managing relevant learning objects' assessments: the right place at the right time
}

\author{
Olivier Catteau, Philippe Vidal and Julien Broisin \\ Institut de Recherche en Informatique de Toulouse \\ University of Toulouse \\ France
}

\section{Introduction}

Annotations are essential when content, form and description of learning objects have to be improved: assessments help teachers to build new and enhance existing resources, whereas suggestions for use allow avoiding former pedagogical mistakes. Reviews submitted by subject matter experts, together with students' comments, represent a crucial source of information to improve pedagogical resources during the re-authoring process.

Learning objects and metadata are often stored into a Learning Object Repository (LOR) that facilitates their distribution and reuse at a wide scale; course designers and teachers can browse repositories to find existing learning resources that match with their pedagogical objectives, and reuse this material into their curriculum. However, this kind of system does not allow collecting relevant annotations because LOR are dedicated to storage and description, they provide no pedagogical features. Annotations are thus not present or not objective, because they are most often restricted to text notes provided by the author of the resource himself. Instead, assessments and suggestions for use become relevant when learning objects have been used in a real learning context, that is when teachers and learners have exploited the pedagogical resources: the feedback step comes later than the diffusion step in the learning object and metadata lifecycle (Catteau et al., 2006).

Since Learning Management System (LMS) represents the most popular system deployed within public and private institutions to deliver learning services, works presented here stand on two main proposals: the collection of annotations through LMS, and their storage within LOR. Communication between these two kinds of systems is based on a standardized and open architecture allowing LMS users to transparently manipulate resources stored into LOR (Broisin et al., 2005), whereas an extension of the Learning Object Metadata standard (IEEE-LTSC, 2002) allows describing global and specific as well as quantitative and qualitative annotations. Assessments and suggestions for use are thus gathered when they become relevant and stored where they have to reside, and can be widely shared and exploited to facilitate several learning processes such as curriculum designs, re-authoring or learning object retrieval. An implementation focusing on Moodle and the Ariadne Knowledge Pool System validates our approach. 


\section{Learning Object Assessment}

Quality represents a growing interest within the research community, as the number of works and tools focusing on this area demonstrates it. Even if it may be unduly risk averse ( $\mathrm{O}^{\prime}$ Reilly, 2002), peer review is commonly operated by research councils in order to ensure scientific quality. In a pedagogical context, because students can learn from their reviewers' comments, peer review is often used in learning processes (Furman \& Robinson, 2003; Gehringer, 2003). Students can even be empowered to take on the role of the teacher to carry out the correction process (Coit \& Stöwe, 2006). To promote enhanced teaching methods, techniques and strategies, the North Dakota State University implemented a policy of cooperative peer review teams. The program, including peer meetings, syllabus review, and classroom observations, was widen to the whole teaching process (McIntyre \& Mehta, 2003). We focus our work on peer reviewing and user comments collected during the feedback step. They are only a part of the quality approach and must be considered as a summative evaluation of a ready-to-use LO. Our work also includes LO suggestions for use that will help teachers building a learning design.

\subsection{Existing Reviewing Systems}

A system such as MemoNote (Azouaou \& Desmoulins, 2006) provides teachers with a personal memory composed of annotations they have made on documents during their various teaching activities. Nevertheless, these annotations are not added into a LOR and cannot be widely shared. On the other hand, the e-learning research and assessment network allows up to four assessors to submit into the LOR quantitative and qualitative peer reviews according to several criteria (Kumar et al., 2005), as shown on figure 1.

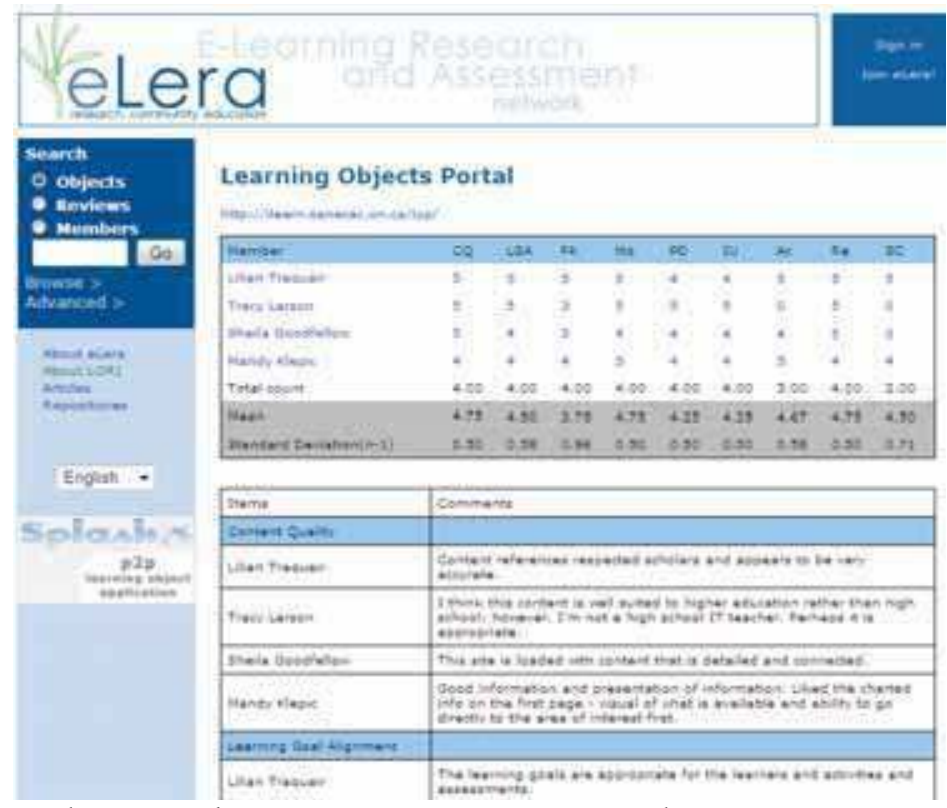

Fig. 1. LORI qualitative and quantitative assessment example. 
Boskic noticed that most of LOR doesn't support quality evaluation, while a few of them include peer reviews and/or suggest a feature for users' comments (Boskic, 2003). Table 1 depicts the results of a study related to features provided by five LOR implementing quality evaluations. Qualitative reviews or comments are always present, whereas quantitative reviews (e.g. five-point scales) required for quality-based sorting (Vargo et al., 2003) are not implemented in two repositories. LORI (Kumar et al., 2005), MERLOT (Multimedia Educational Resources for Learning and Online Teaching, 2009) and Wisconsin Online (Wisconsin Online Resource Center, 2009) distinguish different types of assessor such as subject matter expert, instructional designer, learner, etc. Moreover, criteria used for LO evaluation differ from a LOR to another, according to assessor and LO types (McMartin et al., 2004; SREB Educational Technology Cooperative, 2009; Vargo et al., 2003).

\begin{tabular}{|l|l|l|}
\hline LOR & $\begin{array}{l}\text { Quantitative } \\
\text { Review }\end{array}$ & $\begin{array}{l}\text { Qualitative } \\
\text { Review }\end{array}$ \\
\hline $\begin{array}{l}\text { Evalutech (SREB Educational Technology } \\
\text { Cooperative, 2009) }\end{array}$ & NO & $\begin{array}{l}\text { Peer review by } \\
\text { domain expert }\end{array}$ \\
\hline Harvey Project (OpenCourse.Org, 2009) & NO & $\begin{array}{l}\text { Peer review + } \\
\text { Classroom testing }\end{array}$ \\
\hline LORI (Kumar et al., 2005) & Peer review (up to 4 assessors) \\
\hline $\begin{array}{l}\text { MERLOT (Multimedia Educational Resources } \\
\text { for Learning and Online Teaching, 2009) }\end{array}$ & $\begin{array}{l}\text { Peer review (2 domain experts) } \\
\text { Member comments }\end{array}$ \\
\hline $\begin{array}{l}\text { Wisconsin Online (Wisconsin Online Resource } \\
\text { Center, 2009) }\end{array}$ & Public comments \\
\hline
\end{tabular}

Table 1. LOR implementing quality evaluations

\subsection{Issues}

The previous section pointed out some difficulties that must be solved in order to offer an efficient $\mathrm{LO}$ assessment mechanism:

- despite the need for sharing and reusing this information, most of LOR presented in table 1 store peer reviews, comments and suggestions for use in a specific database, they are not included into metadata;

- specific web systems have been elaborated to manage assessments, they most often differ from the system used to learn and teach.

To tackle these issues, our framework stands on two main proposals: the storage of annotations within metadata (and therefore into LOR), and the collection of annotations through a LMS.

\section{Extending the LOM standard}

\subsection{The LOM annotation category}

The Learning Object Metadata is the most widely-used standard to describe learning objects into a LOR. It offers an Annotation category in order to "enable educators to share their assessments of learning objects, suggestions for use, etc." (IEEE-LTSC, 2002). As shown on figure 2a, a LO annotation is composed of:

- the entity (LOM 8.1) having created the annotation, described using the vCard format; 
- the creation date (LOM 8.2) of the annotation, expressed with the DateTime format; - the description (LOM 8.3) as a LangString represents the content of the annotation.

These descriptors are part of several LOM application profiles, they are mandatory in CanCore (Friesen et al., 2004), recommended in UK LOM Core (UK Metadata for Education Group, 2004), and optional in many application profiles such as SCORM (Advanced Distributed Learning, 2004) or LOM-FR (AFNOR, 2006).

An annotation can be used to describe learning objects assessments or suggestions for use. Each quantitative and/or qualitative annotation is made at a specific time by an entity (e.g. a user, an organization) matching with a specific type of assessor. Annotations can represent a suggestion for use, may be global to the whole content or specific to a criterion. They are useful mostly for a target audience (e.g. a learner, a teacher).

But the LOM standard doesn't take into account neither the role of the entity, nor the type of the annotation (global, specific criterion or suggestion for use), nor the target audience. Moreover, the description element (LOM 8.3) is well-adapted for qualitative review but not for a quantitative one.

\subsection{The extended LOM Annotation Category}

The lacks mentioned above to describe a LOM annotation bring us to propose, as shown on figure $2 \mathrm{~b}$, several modifications to the Annotation Category:

- the extension of the LOM 8.1 structure in order to get a complete Contribute set that includes an Entity together with its Role,

- the Annotation Type element that specifies whether the annotation is global, related to a specific criterion, or describing a suggestion for use,

- the Quality Level element for providing information about quantitative evaluation,

- the Target Audience element that specifies whether the annotation is for learners, teachers, authors or everybody.

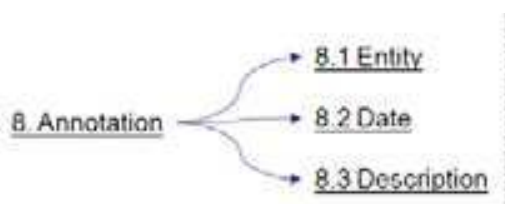

a- Existing LOM.Aninotation Catsgory

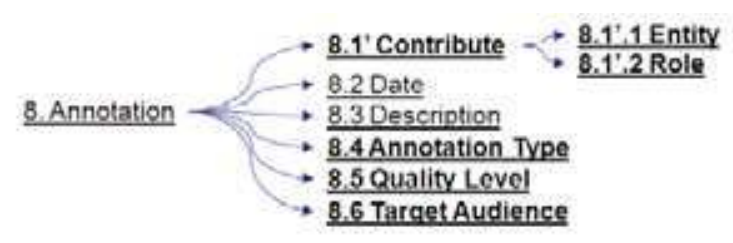

b. Modified LOM.Mnnotation Category

Fig. 2. The existing and modified LOM Annotation categories

These enhancements make it possible to fully describe LO assessments using the LOM metadata standard, but a main drawback remains: the difficulty to collect and store this information. On one hand, few LOR allow users to freely modify metadata (including annotations) of an existing learning object, and LMS are more adapted to LO assessments than LOR on the other hand. Thus, the next section introduces the annotation management service that allows, from a LMS, to add annotations into the metadata of a learning object stored into a LOR. 


\section{Closer to the End User}

\subsection{The Original LOV Design}

The Learning Object Virtualization (LOV) architecture (Broisin et al., 2005) is based on learning technology standards and allows for learning objects virtualization: it offers both a single view of the whole set of resources stored into several heterogeneous LOR, and an easy access to those resources through the use of LMS. This framework illustrated on figure 3 offers a transparent communication between LMS and LOR and allows to (a) query the LOR from the LMS and to retrieve learning objects metadata, (b) download the matching documents on the local host, (c) import the matching documents into the dedicated space of the LMS in order to deploy this resource within a learning design, and (d) index new learning objects into a LOR starting from a LMS. Nevertheless, the original framework does not provide any service related to LO assessment.

\subsection{Annotation Management Service}

As illustrated on figure 3, the Annotation Management Service (AMS) has been introduced into the Virtualization layer. It allows LMS users to submit annotations and to store these assessments into a LOR. The nature of this service makes it only apply to learning resources imported from a LOR into a courseware. Indeed, resources that have been directly uploaded to the LMS by users are not described by metadata, and can't be stored into a LOR.

When an assessment is submitted, data specified by the assessor are transmitted through the AMS to the appropriate LOR. In order to make the process smoother, the service allows for automatic metadata generation by exploiting the learning context of the LMS: entity and role are automatically produced.

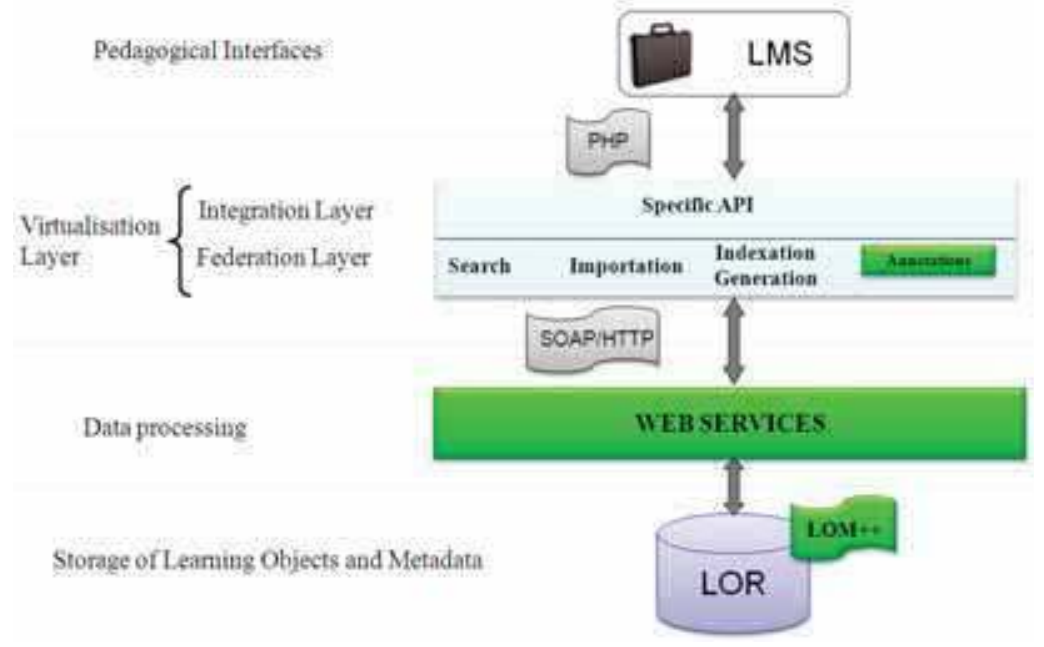

Fig. 3. The improved LOV architecture

The introduction of the AMS into the LOV architecture presents several benefits:

- it allows users to add an annotation when it becomes relevant, that is after the LO exploitation within a LMS; 
- it enables various users, distributed on several LMS, to share annotations stored on multiple LOR;

- criteria used to evaluate a learning object can be customized within the LMS depending on the user role.

Moreover, the storage of annotations within a LOR allows improving the Search Service of the Virtualization layer. Indeed, a teacher editing a courseware and searching for existing learning objects is now able to consult annotations associated to these resources. It thus helps teachers and tutors to:

- Build a learning design or courseware by improving the learning object selection process: editing teachers can sort learning objects according to a quality-based mechanism that takes into account global or personalized criteria weights.

- Avoid pedagogical mistakes during the resource exploitation, and to be aware of the specific challenges or strengths undertaken by the resource.

\section{Implementation: Moodle and the Ariadne repository}

The original LOV architecture has been implemented with two LMS (INES and Moodle), and the GLOBE repositories (GLOBE, 2009) including MERLOT, ARIADNE, EDNA and NIME. The AMS focuses on the cooperation between Moodle (Moodle, 2009) and the LOMbased ARIADNE Knowledge Pool System (KPS) (Duval et al., 2001): annotations are generated from Moodle and stored within the KPS. Because the M in Moodle stands for modular, the new features presented here have been added to the existing LOV module for Moodle, and have only required ten development days.

Roles natively defined by Moodle are the followings: administrator, course creator, editing teacher, teacher, student, and guest. The role "subject matter expert" has thus been created in order to allow peer reviews. On the whole, several types of actors can submit annotations, as depicted in figure 4 .

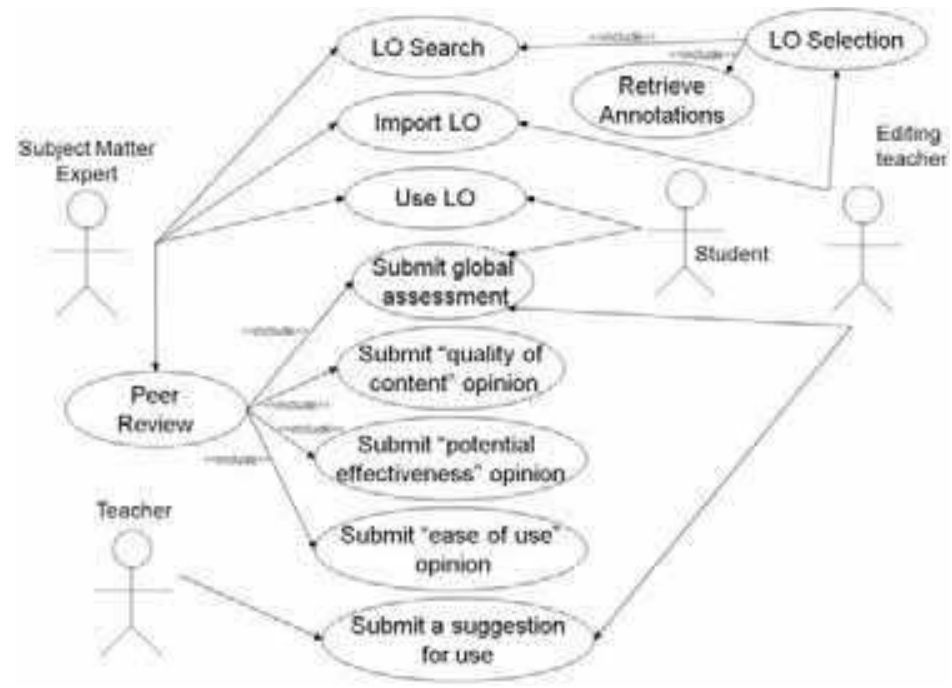

Fig. 4. Annotation use case diagram 
Fast global quantitative evaluations can be made by users via a graphical star rating system illustrated on figure 5. Detailed evaluations consist in filling in one or several forms that include:

- the annotation type which can be global, matching with a suggestion for use or specific to an evaluation criterion. The first implementation suggests criteria defined by MERLOT: Content Quality, Effectiveness, Ease to Use (McMartin et al., 2004);

- the description of the qualitative evaluation;

- a graphical five-point star rating system related to the annotation type. When the annotation type matches with a suggestion for use, this rating system becomes incongruous and is de facto disabled;

- the target audience by selecting everybody, author, learner or teacher option.

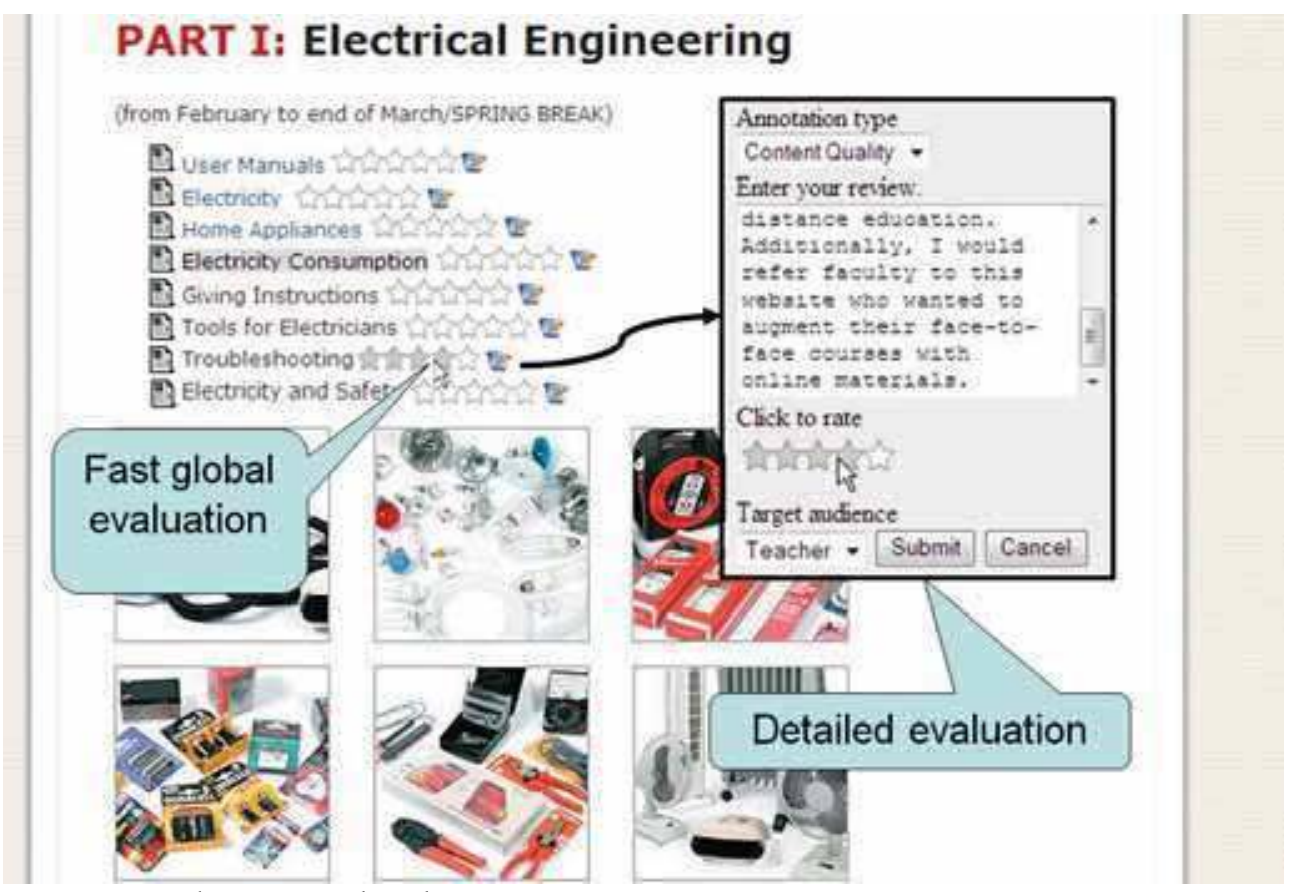

Fig. 5. LO evaluations within the LMS

Each user can submit and modify one annotation per annotation type for a same LO. There is no limit to the quantity of users storing annotations for a same LO. Let us note that the Contribute and Date elements of the LOM Annotation category don't appear on figure 5. Indeed, the vCard entity together with the role can be deduced from the LMS profile of the user, whereas the date can be easily generated.

Annotations submitted by users are transparently stored within the KPS. The UML diagram sequence illustrated on figure 6 represents the required operations to achieve this process:

1. A user submits an annotation through the Moodle interface.

2. Moodle delivers the annotation to the AMS.

3. This last generates the vCard and role of the user, and consults the LO properties in order 
to extract the location of the LOR responsible for its management, together with its matching identifier. Those properties are specified by the Importation Service (see figure 3) during the importation process: it keeps the relationship between the target LOR, the LO and its identifier within the LOR.

4. The AMS sends both the annotation and the LO identifier to the Ariadne Web Services (AWS) responsible for interacting with the repository. The SOAP protocol is used to ensure communications between these entities.

5. The AWS add the annotation to the metadata item describing the matching learning object and stored into the KPS.

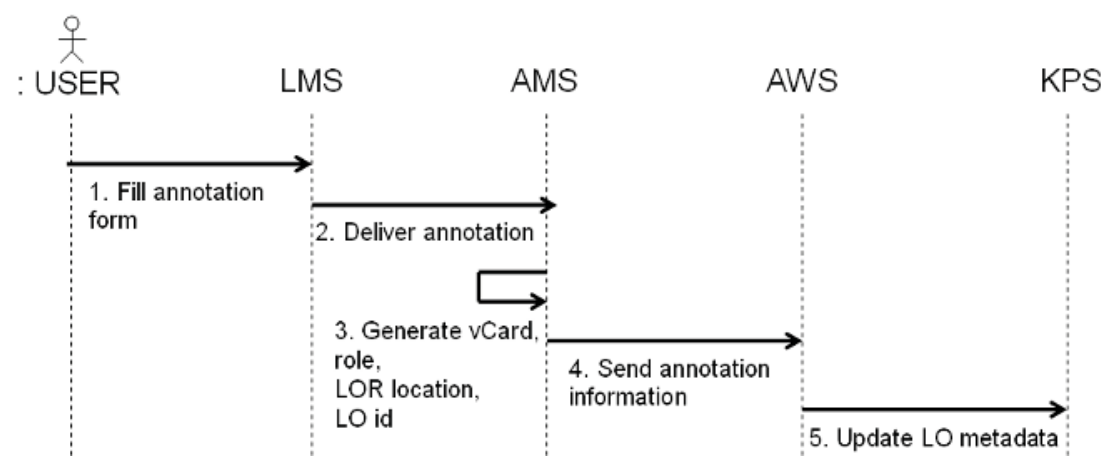

Fig. 6. Annotation submission sequence

The AMS is now deployed within the International E-Miage (IEM) learning environment, a digital campus that delivers degrees to French and foreign lifelong learning students (Cochard \& Marquie, 2004). All experts, tutors, and learners located in the various IEM exploitation centres are thus able to submit their own annotations, and to benefit from assessments suggested by the whole community. First results will be collected at the end of the semester and will help us to enhance the AMS according to users' requirements.

\section{Conclusion and Perspectives}

We presented in this paper an open architecture that facilitates learning objects assessments and suggestions for use. This framework allows users to submit annotations directly from a LMS, and to store these annotations into a LOR for share and reuse purposes. Thus, annotations are submitted and retrieved when and where they become relevant. They can come from various LOR and be used in multiple LMS.

The Annotation Management Service has been successfully implemented for a specific LMS communicating with a LOR, and has just been deployed within the various exploitation centres of an international digital campus. In order to widely benefit from this work, both the modifications applied to the Annotation Category of the LOM standard and the vocabulary used for roles, annotation types and quality levels should be adopted by consensus. Other metadata standards such as ISO MLR are being elaborated; a proposal will be suggested in this direction. Even if success and efficiency of learning objects assessments strongly depend on end users' motivation and involvement, the huge number of MERLOT statistics about peer reviewing and user comments makes us confident about this approach. 
The vocabulary of annotation types should automatically be adapted to the user role: a subject matter expert should fill in each criterion of a peer review, whereas other actors may submit global evaluations. This would allow to improve the LO selection process by attributing different weights to each criterion. Moreover, it should also be useful to customize evaluation criterion according to the learning object type: a slide is not annotated and evaluated as if it were an experiment. Some specific criteria should thus be defined for each existing type of learning object.

Some systems allow annotations to be made forthright on documents by teachers or students during their various pedagogical activities. As future works, we plan to consider in situ annotations in order to encourage users to generate annotations. Indeed, time is needed to consider a learning object from a higher point of view and to conceive a general annotation, whereas an annotation related to a specific image or paragraph can be achieved while reading the learning resource (Marshall, 1997).

Finally, we want to investigate deeper the opportunity to offer to end-users a personal annotation feature. Indeed, some annotations make only sense for their author (e.g. "not understood, should go over the basics"), whereas some others have to be shared with the whole community.

\section{References}

Advanced Distributed Learning (2004), “SCORM: Sharable Content Object Reference Model Information", available at http://www.adlnet.org/

AFNOR (2006), “Technologies de l'information pour l'éducation, la formation et l'apprentissage - Profil français d'application du LOM (LOMFR) - Métadonnées pour l'enseignement", Norme NF Z76-040.

Azouaou, F., Desmoulins C. (2006) "A Flexible and Extensible Architecture For ContextAware Annotation in E-Learning", The 6th IEEE International Conference on Advanced Learning Technologies (ICALT'06), pp. 22-26.

Boskic, N. (2003), "Learning Objects Design: What do Educators Think about the Quality and Reusability of Learning Objects?", International Conference on Advance Learning Technologies (ICALT), 2p.

Broisin, J., Vidal, P., Baqué, P., Duval, E. (2005) "Sharing and Reusing Learning Objects: Learning Management Systems and Learning Object Repositories", EDMEDIA, 8p.

Catteau, O., Vidal, P., Broisin, J. (2006) “A Generic Representation Allowing for Expression of Learning Object and Metadata Lifecycle", International Conference on Advanced Learning Technologies (ICALT'06), pp. 30-33.

Cochard, G.M., \& Marquie, D. (2004) “An e-learning version of the French Higher Education Curriculum 'Computer Methods for the Companies Management'". 18th IFIP World Congress Computer, pp. 557-572.

Coit, C., Stöwe, K. (2006) "Peer Review for Life", International Conference on Advance Learning Technologies (ICALT), 3p.

Duval, E., Forte E., Cardinaels, K., Verhoeven, B., Van Durm, R., Hendrikx, K., Wentland Forte, M., Ebel, N., Macowicz M., Warkentyne, K., Haenni F. (2001), “The Ariadne Knowledge Pool System", Communications of the ACM, vol. 44, issue 5, pp. 72-78.

Friesen, N., Fischer, S., Roberts, A. (2004) "CanCore Guidelines Version 2.0: Annotation Category", 10 p., available at http:/ / www.cancore.org/ 
Furman, B., Robinson, W. (2003), “Improving engineering report writing with Calibrated Peer ReviewTM", 33rd ASEE/IEEE Frontiers in Education Conference, 3p.

Gehringer, E.F. (2003), "Building resources for teaching computer architecture through electronic peer review", Workshop on Computer Architecture Education, 8p.

GLOBE (2009), available at http:/ / www.globe-info.net/

IEEE-LTSC. 1484.12.1-2002 (2002) "IEEE Standard for Learning Object Metadata", 40 p

Kumar, V., Nesbit, J., Han, K. (2005), "Rating Learning Object Quality with Distributed Bayesian Belief Networks: the why and the how", International Conference on Advance Learning Technologies (ICALT), 3p.

Marshall, C.C. (1997), "Annotation: from paper books to the digital library", 2nd ACM Conference on Digital Libraries, 10p.

McIntyre, C., Mehta, S. (2003), “A program for Faculty Peer Review of Teaching at North Dakota State University", 33rd ASEE/IEEE Frontiers in Education Conference, 5p.

McMartin, F., Wetzel, M., Hanley, G. (2004), “Ensuring Quality in Peer Review”, Joint ACM/IEEE Conference on Digital Libraries (JCDL), 1p.

Moodle (2009), available at http:/ / www.moodle.org/

Multimedia Educational Resources for Learning and Online Teaching (MERLOT) (2009), available at http:// merlot.org/

OpenCourse.Org (2009), Harvey Project, available at http:// harveyproject.org/

O'Reilly, J. (2002), "Risk, adventure and tyranny of peer review", Engineering Science and Education Journal, December 2002, pp. 251-253

Southern Regional Education Board (SREB) Educational Technology Cooperative (2009), Evalutech, available at http://www.evalutech.sreb.org/

UK Metadata for Education Group (2004), "UK Learning Object Metadata Core, Draft 0.2", 56p., available at http://www.cetis.ac.uk/profiles/uklomcore/

Vargo, J., Nesbit, J.C., Belfer, K., Archambault, A. (2003), “Learning Object Evaluation: Computer-Mediated Collaboration and Inter-Rater Reliability", International Journal of Computers and Applications, Vol. 25, No. 3, 8p.

Wisconsin Online Resource Center (2009), Wisc-Online, available at http://wisconline.com/ 


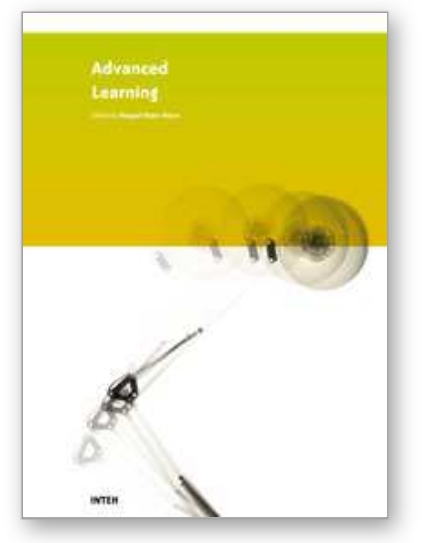

\author{
Advanced Learning \\ Edited by Raquel Hijn-Neira
}

ISBN 978-953-307-010-0

Hard cover, 444 pages

Publisher InTech

Published online 01, October, 2009

Published in print edition October, 2009

The education industry has obviously been influenced by the Internet revolution. Teaching and learning methods have changed significantly since the coming of the Web and it is very likely they will keep evolving many years to come thanks to it. A good example of this changing reality is the spectacular development of eLearning. In a more particular way, the Web 2.0 has offered to the teaching industry a set of tools and practices that are modifying the learning systems and knowledge transmission methods. Teachers and students can use these tools in a variety of ways aimed to the general purpose of promoting collaborative work. The editor would like to thank the authors, who have committed so much effort to the publication of this work. She is sure that this volume will certainly be of great help for students, teachers and researchers. This was, at least, the main aim of the authors.

\title{
How to reference
}

In order to correctly reference this scholarly work, feel free to copy and paste the following:

Olivier Catteau, Philippe Vidal and Julien Broisin (2009). Managing Relevant Learning Objects' Assessments: the Right Place at the Right Time, Advanced Learning, Raquel Hijn-Neira (Ed.), ISBN: 978-953-307-010-0, InTech, Available from: http://www.intechopen.com/books/advanced-learning/managing-relevant-learningobjects-assessments-the-right-place-at-the-right-time

\section{INTECH}

open science | open minds

\section{InTech Europe}

University Campus STeP Ri

Slavka Krautzeka 83/A

51000 Rijeka, Croatia

Phone: +385 (51) 770447

Fax: +385 (51) 686166

www.intechopen.com

\section{InTech China}

Unit 405, Office Block, Hotel Equatorial Shanghai

No.65, Yan An Road (West), Shanghai, 200040, China

中国上海市延安西路65号上海国际贵都大饭店办公楼 405 单元

Phone: +86-21-62489820

Fax: $+86-21-62489821$ 
(C) 2009 The Author(s). Licensee IntechOpen. This chapter is distributed under the terms of the Creative Commons Attribution-NonCommercial-ShareAlike-3.0 License, which permits use, distribution and reproduction for non-commercial purposes, provided the original is properly cited and derivative works building on this content are distributed under the same license. 